\title{
Economic Assessment of a PV/Diesel/Battery Hybrid Energy System for a Non-Electrified Remote Village in Nigeria
}

\author{
Abba Lawan Bukar ${ }^{1}$, Babangida Modu ${ }^{1}$, Zainab Musa Gwoma ${ }^{1}$, Musa Mustapha ${ }^{1}$, Abdulrahman \\ Babagana Buji ${ }^{1}$, Musa Baba Lawan ${ }^{1}$, Ibrahim Tijjani ${ }^{1,2}$, Umar Ali Benisheik ${ }^{1}$, Adam Bukar ${ }^{1}$ and Kalli \\ Baba Mai $^{1}$
}

\begin{abstract}
Nigeria has a large number of remote areas that are not being electrified; this is because the power generated is less than the demand of the country. Garundole village is a typical example, with a population of about 270 is not connected to the main grid. Currently load shedding is being practiced by the Power Holding Company of Nigeria (PHCN) to dispatch the power being generated. Moreover, majority of the people leaving in these remote villages depend mostly on diesel power generator. Thus, there is a need to have an independent generating station for such kind of remote village to ease the living conditions of its inhabitants. This paper therefore, reports the economic assessment of PV/diesel/battery hybrid off-grid energy system as an alternative solution to these remote villages. In this regard, three different system configurations is being be studied and analyzed using HOMER optimization software to carry out the economic analysis of the systems and its technical feasibility. The systems include; standalone diesel generator, hybrid PV/diesel with battery storage and hybrid PV/diesel without battery storage. The result obtained from the study shows that a hybrid PV/diesel with a backup battery has the potential capabilities of replacing diesel powered generator used by individual households independently.
\end{abstract}

Index Terms-Renewable Energy; Cost of Energy, Net Present Cost, Homer Software; Photovoltaic.

\section{INTRODUCTION}

Nigeria has a large number of remote villages that lack electricity supply. The possibility of connecting them to the grid in the near future is less, because the power generated is less than the demand of the country and due to poor grid facilities [1]. Moreover, there has been always a drop in the power generation due to poor funding, poor strategies in system maintenance and political situation of the country [2]. At present out of the 170 million population of Nigeria, only $40 \%$ of the Nigerian household have access to the National utility supply and out of which only $10 \%$ of the households in the rural area have access to electricity $[1,3$,

4]. The energy demands of these villages are extremely low and with the daily average energy demand vary in the range of 0.5- $2 \mathrm{kWh}$ per household. Electrical loads usually found in these villages including TV, fan, lighting and refrigerators etc. At present, majority of the villagers used small diesel generators of power range from 2.5 to $3.5 \mathrm{kVA}$ to cover the power demand of their households [2]. And the operations of these generators are limited to night periods only. In

Published on January 11, 2017.

1 Department of Electrical and Electronics Engineering, Faculty of Engineering, University of Maiduguri, Maiduguri, Borno State, Nigeria.

2 Department of Electrical and Electronics Engineering, Ramat Polytechnic Maiduguri, Borno State, Nigeria. addition, these small generators are not reliable due to their frequent faults and also pollute the environment. The price of diesel fuel in Nigeria is relatively high since it amount to almost 1.2 USD per litre as a result not all villagers can afford these small generators daily. Therefore, using such small generators would not bring a durable solution to all these problems. Therefore, in order to overcome the problems stated above, and to maintain a sustainable and healthy environment, Photovoltaic (PV) systems can be installed. As photovoltaic systems are nowadays used as an alternative source of energy worldwide and can be installed as off-grid and on-grid system.

Nigeria has a high solar energy potential $[5,6]$ and there is a remarkable variation of solar radiation intensity from the north to the south of Nigeria as shown in Fig. 1. The radiation ranging from $7000 \mathrm{Wh} / \mathrm{m}^{2}$ in the farthest north-eastern to $4000 \mathrm{Wh} / \mathrm{m}^{2}$ toward the southern part of the country [2]. Based on the studies and researches carried out by various researchers, their result shows that the solar energy in the northern part of the country if fully harness, it could be used to electrify remote villages that are not connected being connected to the grid. Solar photovoltaic systems are implemented in countries having a monthly average daily solar radiation of $3-6 \mathrm{kWh} / \mathrm{m}^{2}$ as additional energy source with an aim of reducing fossil-fuel to generate electricity [7].

In this paper, a non-electrified remote village in the north-eastern part of Nigeria with a considerable number of Nigerians had been selected for implementing the study of a PV/diesel/battery hybrid power system for a remotely area in Yobe State, Nigeria using HOMER optimization software. The technical feasibility and system ranking based on their net present cost (NPC) is automatically estimated by the software. To determine the best system for the proposed site, system configuration with battery and without battery are analysed in order to minimize dependency on fossil fuels. Also, a standalone diesel generator system is also analysed and it viabilities is assessed.

The paper is organized into five sections. Section 1 presents a brief introduction of the current state of power system condition in Nigeria. Section 2 a discussion on HOMER software is provided. In Section 3, a discussion on the input parameters to be used in order to carry out simulation using HOMER Software, while Section 4 presents the system description and specification of components to be used in the design. The Operating strategies of the hybrid diesel/PV/battery system and aspect concerning its economic analysis are presented in Section 5 and 6 respectively. Section 7 presents the results and discussions. Lastly, a conclusion of the work is given in section 


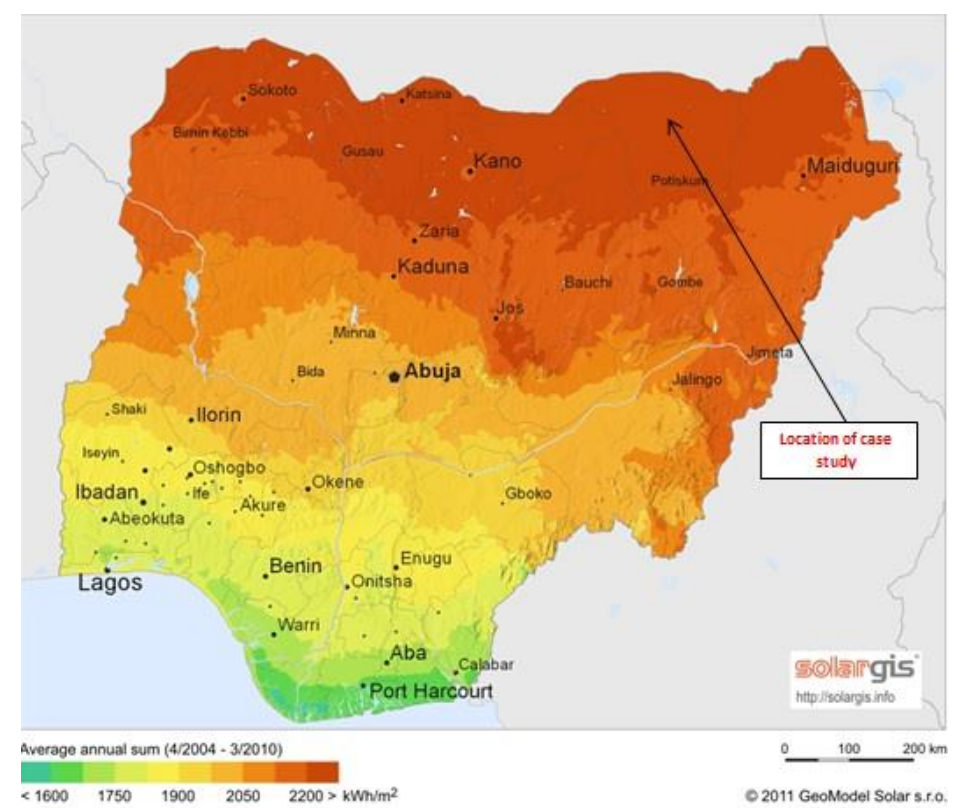

Fig. 1. Annual average of daily sums of solar irradiance for Africa [10].

\section{HOMER SOFTWARE}

HOMER [9] is a computer software model developed in 1993 by the United State (US) National Renewable Energy Laboratory (NREL) specifically to meet the needs of renewable energy industries. HOMER software assists in the design of micro power systems of different varieties and simplifies the task of evaluating different design option for grid connected power and off-grid systems (autonomous) for remote areas, standalone and distributed generation applications.
Basically HOMER performs simulation, optimization and sensitivity analysis. HOMER models a system and defines its feasibility and life cycle. HOMER software also has the capability of carrying out simulation on different system arrangement and comes up with the optimal selection in the optimization process. In the sensitivity analysis process, HOMER carry out several optimizations under a certain range of inputs to account for uncertainty in the model inputs. A comprehensive HOMER software explanation on can be found in [10].

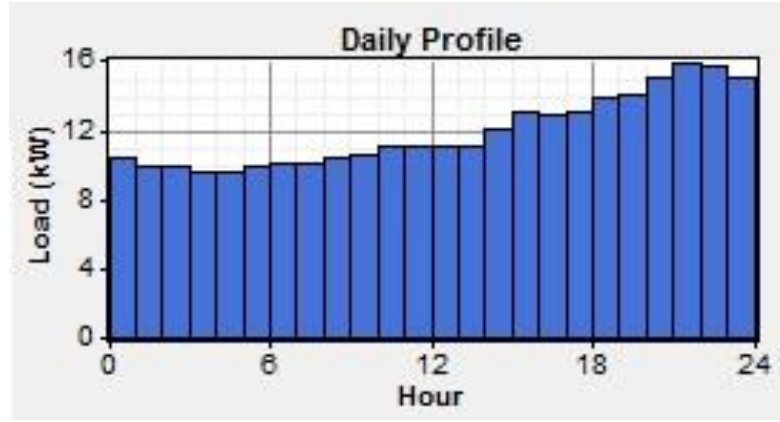

Fig. 2. Daily load profile of Garundole village.

\section{DESCRIPTION OF INPUT PARAMETER}

In order to carry out simulation using HOMER Software, parameters like load profile, solar irradiance of the location for study, the cost of fuel to run the generator, the cost of each component to be used, the power to be generated are required to determine the optimal system configurations. The parameters needed in this design of PVdiesel-storage hybrid system would be explained in detail the following sub-section.

\section{A. Garundole Village Load Profile}

In this study, a remote village called Garundole located in Yobe State, Nigeria was selected to test the viability of the
PV-Diesel-Storage hybrid system. According to the information obtain from the district head of this remote village, the inhabitants are mainly cattle breeders and farmers. The village has a population of about 270, 124 houses (320 rooms), 1 block (5 rooms) of health care centre, 3 blocks (7 rooms) used for primary school pupils and a non-electrified market which is made up of shrubs. The villagers get their drinking water from an artesian well. The economic situation in Garundole village is moderate, with the income of the villagers not exceeding 1500 USD.

The daily energy needs are very low in such villages. Ceiling fans, TV, lighting bulbs and refrigerators are commonly the load in that remote village. The majority of the households in the village are made of wood, while 
cooking and baking bread is done using wood fuel. Kerosene lamps are also used for lighting purpose.

Based on the background information of the remote village and considering the economic situation of its inhabitants, the village requires $17 \mathrm{~kW}$ peak demand, with a based demand of about $6 \mathrm{~kW}$. The load requirement differs throughout the day as it is shown in the daily load profile of the remote area in Fig. 2. The maximum demand occurs during the night hour, this is because the inhabitants are back home by that hour of the day from their normal business i.e. farming and cattle breeding. Also, some of the family members would be expected back home at noon for their lunch and rest, this also cause the demand to increase at that hour. However, during the morning and afternoon hour users will not be at home.
Furthermore, as shown in Fig. 3, it can be noticed that load requirement changes each month. Usually the hottest month in the northern part of Nigeria start from January to April, with a temperature of about $38-40{ }^{\circ} \mathrm{C}$ as presented in Fig. 4. During that period the load requirement would be a little bit higher as compared to the subsequent ones. Also from the May to August of each each is the raining season, the weather in that period is cooler when the rain falls as compared to the month of January to April and are characterized with a temperature of about $22-30{ }^{\circ} \mathrm{C}$ and from early October-December the winter period start, these periods are characterized by a cloudy and cold weather. Thus, electricity demand would be less, especially for cooling purposes (e.g. Fan).

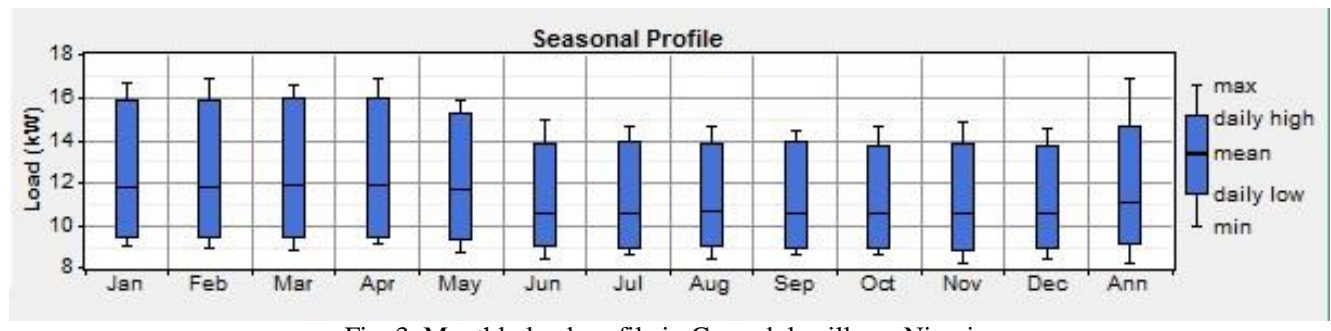

Fig. 3. Monthly load profile in Garundole village, Nigeria.

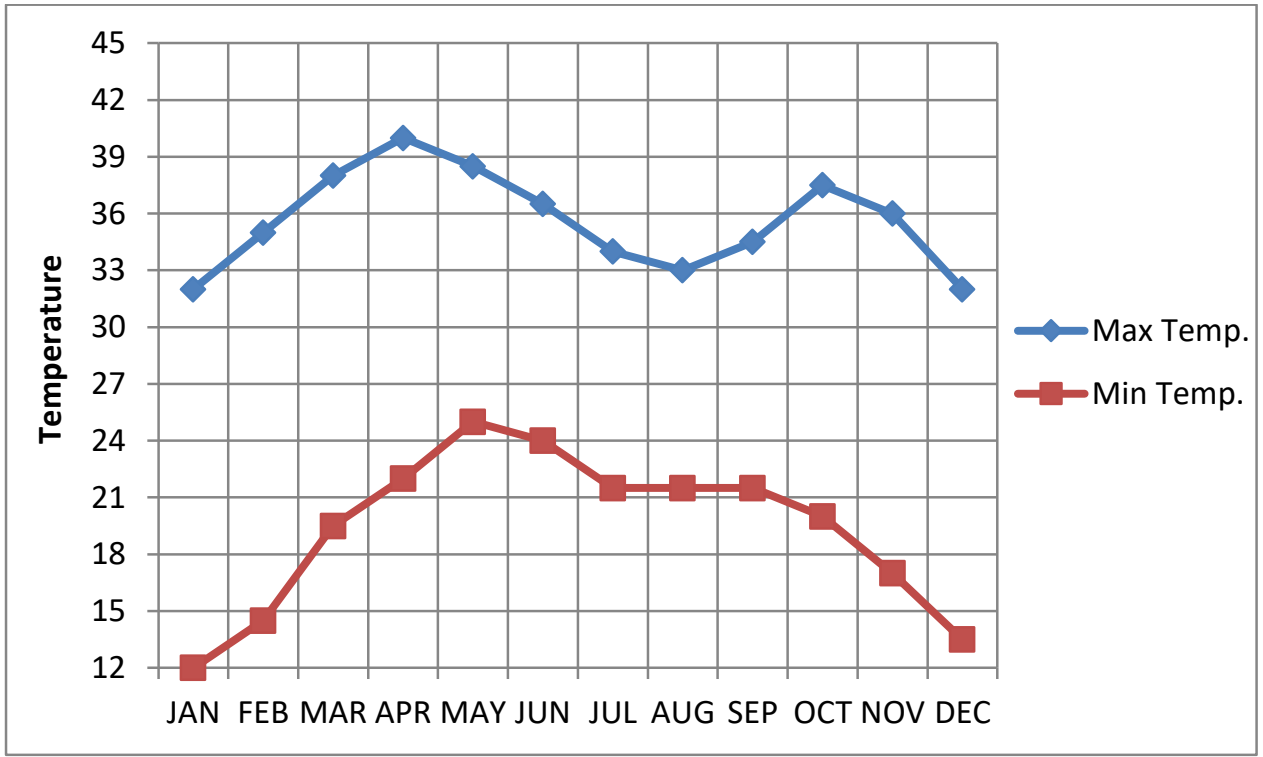

Fig. 4. Average minimum and maximum temperature over the year [13]

\section{B. Solar Radiation}

From the Solar Irradiance figures obtain from NASA and is depicted in Fig. 5, it can be noticed that the months with high solar irradiance is from January to April, while less solar irradiance start from May up to September. This relates to the load requirement as discussed earlier (refer to Fig. 3). After inserting the solar radiation of each month, HOMER software automatically generates the clearness index, this is illustrated in Fig. 6. And $5.51 \mathrm{kWh} / \mathrm{m}^{2} /$ day was estimated to be the scaled annual average of the solar irradiance. 
Solar Irradiance figures

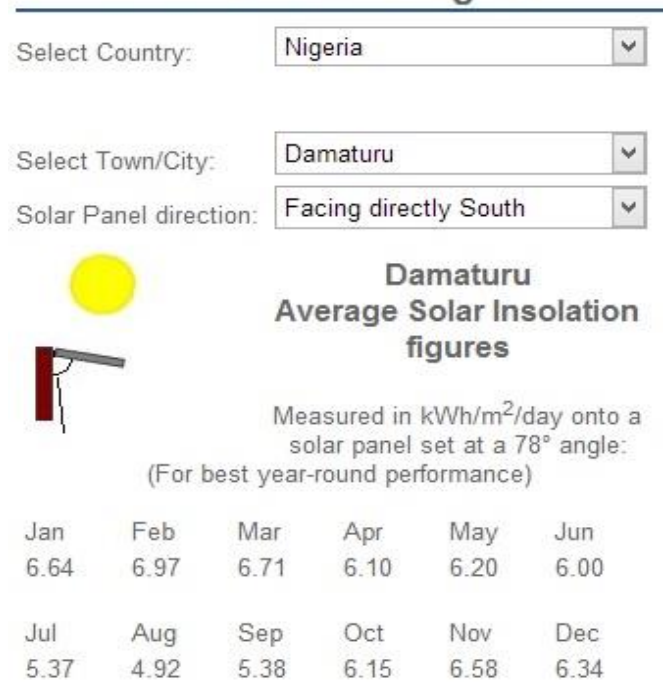

Fig. 5. Solar irradiance source figure [14].

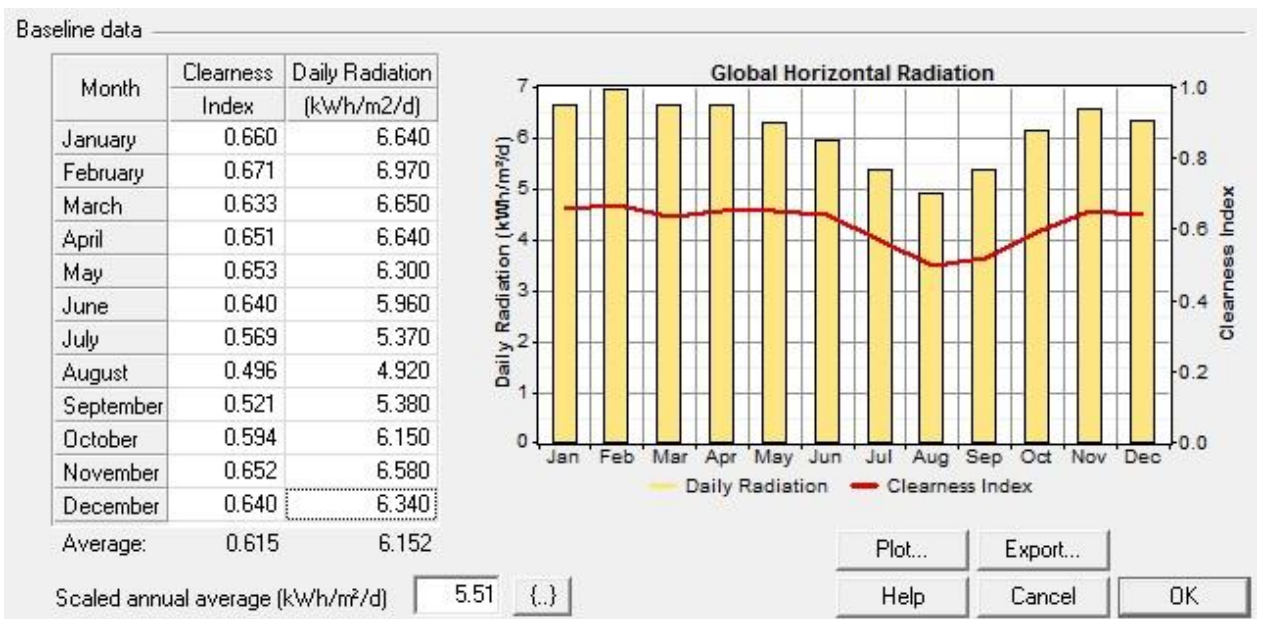

Fig. 6. Annual solar radiation for the Garundole village and the clearness index automatically set by HOMER.

\section{Price of Diesel}

Currently [13] the official price of diesel in Nigeria is 165 NGN per Litre, which equivalent to 1.01 USD. Unfortunately the price in cities is different from the price in remote areas, especially in the Northern part of Nigeria where few filing station area found. Therefore, in this simulation the prices of diesel to be considered is 180 Naira per litre (1.059 USD per litre).

\section{SYSTEM DESCRIPTION AND SPECIFICATION}

Four components are to be considered in the design of the of the hybrid PV/diesel energy system. These are: The PV modules, the batteries, the converter and the generator. Fig. 7 shows the design configuration of the hybrid system proposed for the remote village of Garundole using HOMER. All the system costs are converted to US dollar equivalent, because HOMER software is designed to accept only US dollar as input data for system cost. Table I shows the specification of the component to be used in the design.

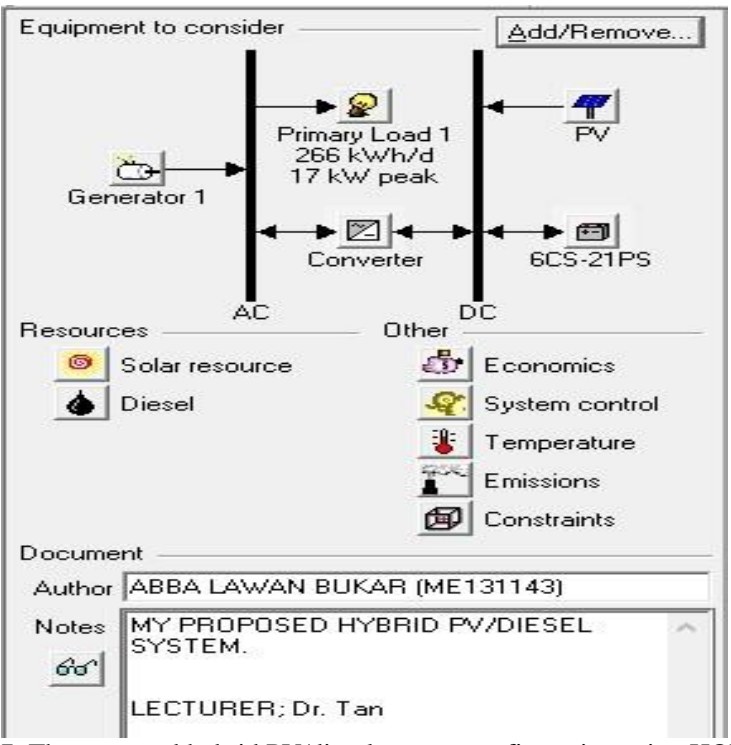

Fig. 7. The proposed hybrid PV/diesel system configuration using HOME. 
TABLE I: Specification Of Components To Be Used In The Design Of The Proposed Hybrid System

\begin{tabular}{ll}
\hline \hline Description & Specification \\
\hline PV & \\
PV model [14] & TDC-P250-60 \\
Size & $20 \mathrm{~kW}$ \\
Capital cost/replacement cost & 5600 USD per kW \\
Operating and maintenance cost & 10 USD per year \\
Life & 25 year \\
Material & Polycrystalline silicon \\
Diesel generator & \\
Generator Model [15] & UC80E \\
Rated power & $20 \mathrm{~kW}$ \\
Capital cost & 300 USD per kW \\
Replacement cost & 270 USD per kW \\
Operating and maintenance cost & 0.023 USD per hour/kW \\
Fuel capacity & $280 \mathrm{~L}$ \\
Fuel consumption & 22 litre /hour \\
Inverter & \\
Inverter model [16] & JKS 1-6kW \\
Rated power & $20 \mathrm{~kW}$ \\
Capital cost & 300 USD per kW \\
Replacement cost & 300 USD per kW \\
Operating and maintenance cost & 7 USD per year \\
Lifetime & $15 y e a r s$ \\
Conversion efficiency & $95 \%$ \\
Storage battery & \\
Type of battery [17] & Surette 6CS-21PS \\
Nominal voltage & $6 \mathrm{~V}(12 \mathrm{~V})$ \\
(2 batteries per string) & 1150 Ah \\
Initial cost & \\
Replacement cost & 1100 USD \\
State of charge & $40 \%$ \\
Nominal energy capacity of each battery & $6.94 \mathrm{kWh}$ \\
Operating and maintenance cost & 7 USD per year \\
Life span & $15 \mathrm{year}$ \\
\hline \hline & \\
\hline & \\
\hline &
\end{tabular}

\section{A. Sizing of the PV Modules}

For this design, a PV array with $20 \mathrm{~kW}_{\mathrm{p}}$ was considered enough to cater for the peak demand of electricity of $17 \mathrm{~kW}_{\mathrm{p}}$ required by the remote area, so that the excess would be used in charging the battery. A TDC-P250-60 polycrystalline silicon PV model was chosen for the design, each module is rated $250 \mathrm{~W}_{\mathrm{p}}$ [14]. In order to obtain the 20 $\mathrm{kW}$ output from the PV modules, a total number of 80 modules were arranged together. It should be noted that this PV only generates electricity during the daytime, at night there is no generation. And sometimes, during the raining period the PV cannot generate as well. For these reasons, a PV system requires either or both batteries storage and a generator set to for a continuous supply of power.

In the simulation, the effect of temperature change is also considered, because PV module is less efficient when the temperature increase to a certain level [18, 19]. The manufacturer also specified the nominal operating cell temperature at $47+/-2{ }^{\circ} \mathrm{C}$ and the $\mathrm{PV}$ module efficiency at $14.40 \%$ under standard test condition. Other detailed for the $\mathrm{PV}$ module used in this design are presented in Table I.

\section{B. Diesel Generator}

Since the peak demand of the remote village is $17 \mathrm{~kW}$ and usually generators are sized to cater for the peak demand [20], therefore a $20 \mathrm{~kW}$ diesel generator was chosen for the design. The $3 \mathrm{~kW}$ excess remaining will serve as a spinning serve which will cater for future load if the need arises. Perhaps the diesel generator only operates when the battery bank couldn't supply the demand and something the PV will not operate as it is expected during the raining season, so the generator will serve as a backup in this design.

\section{Storage Battery}

Surrette 6CS-21PS battery was chosen as the storage element in this design [17]. The battery has a nominal voltage of $6 \mathrm{~V}$. In order to get a nominal voltage of $12 \mathrm{~V}$ which is required in the inverter unit, two batteries are connected in series to form a string. The batteries are configured in such a way that each string consists of two batteries. To get the energy capable of meeting the demand for the whole night up to sun-rise, a total number of 5 strings were considered. This means that a total number of 10 batteries were used in the storage unit, with $12 \mathrm{~V}$ as the nominal bus voltage. To assess the performance of the system and in case if there is no generation from the PV, the number of batteries is varied from 1 to 5 strings.

\section{Inverter}

The inverter rating was made based on the output of the PV array selected for the design. Since the PV gives an output of $20 \mathrm{~kW}$, a $20 \mathrm{~kW}$ inverter is selected in order to fully convert the output of the PV array. The inverter has 92-95\% efficiency as specified by the manufacturer with a life span of 15 years. The operating and maintenance cost of the inverter is 7 USD per year. The initial and replacement cost of the inverter is 300 USD per $\mathrm{kW}$. 


\section{Operating Strategies Of the HYbrid DiESEL/PV/ BATTERY SYSTEM}

Load following dispatch strategies is used in operating the proposed hybrid PV/diesel configuration. The load following dispatch strategy is an option in the HOMER software, such that the generator will produce the required energy to cater the demand of load only. The charging of the battery would be done by the PV, so that whenever the generator is forced to operate, it would only generate to supply the load requirement without charging the battery.

The DC output from the PV is converted into an AC source using an inverter. The charging of the batteries starts as soon as the sunrise on each day, because there would be an excess power generation from the PV at that moment and the load during that hour is low compared to midday hour where the demand is high. And in a situation where the PV array and battery bank are not sufficient to meet the load requirement, the generator set is forced to start.

\section{ECONOMIC ANALYSIS}

Parameters such as project lifetime and the annual real interest rate are important economic input parameters needed for HOMER simulation. The total net present cost of all systems is ranked in ascending by HOMER at the end of the simulation. Apart from that, in order to obtain the optimal results of different system configurations, the levelized cost of energy is also considered to obtain a convenient metric for comparison. In the following section, all these economic parameters will be discussed.

\section{A. Annual Real Interest Rate}

This can be calculated from Eq. (1), and it is the discount rate which is used to convert between the annualized costs and one-time costs [21, 22]. Annual real interest rate,

$$
i=\frac{i^{\prime}-f}{1+f}
$$

Where, $f$ is the inflation rate and $i^{\prime}$ is the nominal interest rate. At present, the annual inflation rate and the nominal interest rate for Nigeria as of November 2014 are $7.90 \%$ and $10.2 \%$ respectively $[23,24]$. Therefore, $2.13 \%$ annual real interest was used in this simulation.

\section{B. Net Present Cost (NPC)}

The net present cost also known as the life cycle cost, include the cost of maintenance, capital cost, fuel cost, replacement cost, non-fuel operation cost etc., spent throughout the lifetime of the project [21]. The HOMER software ranked the optimization results obtain based on the net present cost (NPC) and can be calculated from Eqs. (3) and (4).

$$
\begin{gathered}
C_{N P C}=\frac{C_{a n n, t o t}}{C R F(i, N)} \\
C R F(i, N)=\frac{i(1+i)^{N}}{(1+i)^{N-1}}
\end{gathered}
$$

Where, $C_{\text {ann,tot }}$ is the total annualized cost (USD/year) which includes fuel cost, maintenance cost, operating cost, replacement cost, and capital cost. $i$ denotes the real interest rate in (\%), $\mathrm{N}$ denotes the lifetime of the project (in year) and CRF, which is the capital recovery factor is the ratio used in calculating he present worth of a series of equal cash flow.

\section{Levelized Cost of Energy (LCOE)}

This is the average cost of useful electricity produced by system per kilowatt kilowatt (USD/kWh) and is defined as follows [21]

$$
C O E=\frac{C_{a n n, t o t}}{E_{\text {prim }, A C}+E_{\text {prim }, D C}}
$$

Where;

$C_{\text {ann,tot }}$ Denote the total annualized cost (USD/year),

$E_{\text {prim }, D C}$ Denote the DC primary load served $(\mathrm{kWh} /$ year) and

$E_{\text {prim }, A C}$ Denote the AC primary load served $(266 \mathrm{kWh} /$ day $\times$ 365day) $(\mathrm{kWh} /$ year $)$.

\section{RESULTS AND DISCUSSIONS}

Simulation was performed by comparing three different configurations, i.e. standalone diesel system, hybrid PV/diesel system without battery and hybrid PV/diesel system with battery (Fig. 8a and 8b). The simulation is based on 25 year projection period and $2.13 \%$ annual interest as calculated earlier section 6(i). The number of batteries is varied from 4 units to 40 units, while the capacity of the PV is varied for $0,10,15$ and $20 \mathrm{~kW}$. 


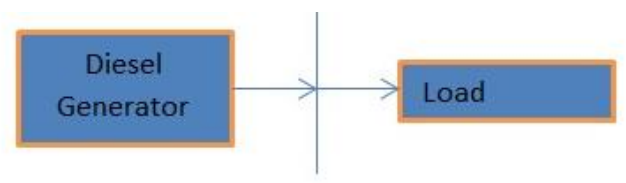

AC Bus

(a)

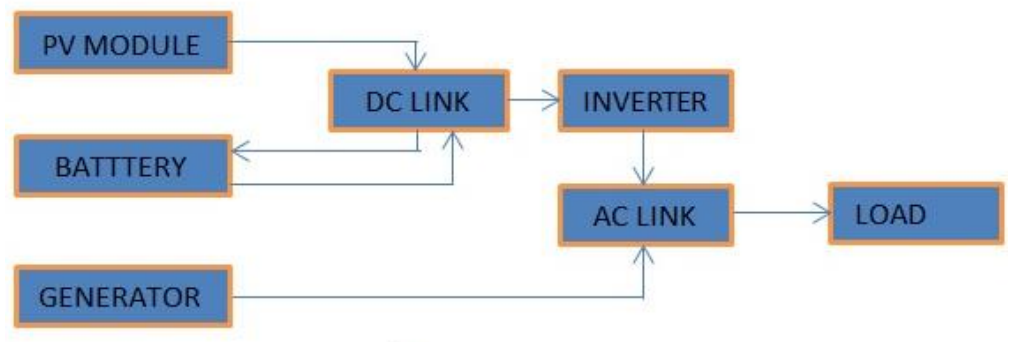

l(b)

Fig 8. (a) \& (b) The block diagrams for the standalone diesel system and the hybrid PV/diesel system

\section{A. Standalone diesel generator}

Based on the Simulation results obtain, stand-alone diesel happens to be the one with low cost of energy and net present cost when compared with the other studied configuration. The total net present cost (NPC) and the levelized cost of energy (LCOE) of the stand-alone at a diesel price of 1.059 USD per Litre is 614,077 USD and 0.495 USD per $\mathrm{kWh}$ respectively. The standalone diesel generator can generate up to $97,090 \mathrm{kWh}$ of electrical power per year, with $\mathrm{CO}_{2}$ emission of $100,826 \mathrm{~kg} / \mathrm{yr}$. In [25], David Biello in his study states that when a high level of
$\mathrm{CO}_{2}$ (e.g. Trillion tons) is released to the atmosphere, it will lead to a partial peak warming of about $2{ }^{\circ} \mathrm{C}$ and this can be described as a hazardous point. Thus, the level of carbon emission should be controlled far below trillion tons in order to minimize the effect of global warming. Fig. 9 shows the summary of cash flow of the net present cost (NPC) for the stand alone diesel system with breakdown for different cost associate to it. Fuel consumption is the main expenses of the standalone diesel system, followed by the cost of operating and maintenance of the system. This is an indication that a lot of money is being spent on fuel for running the system.

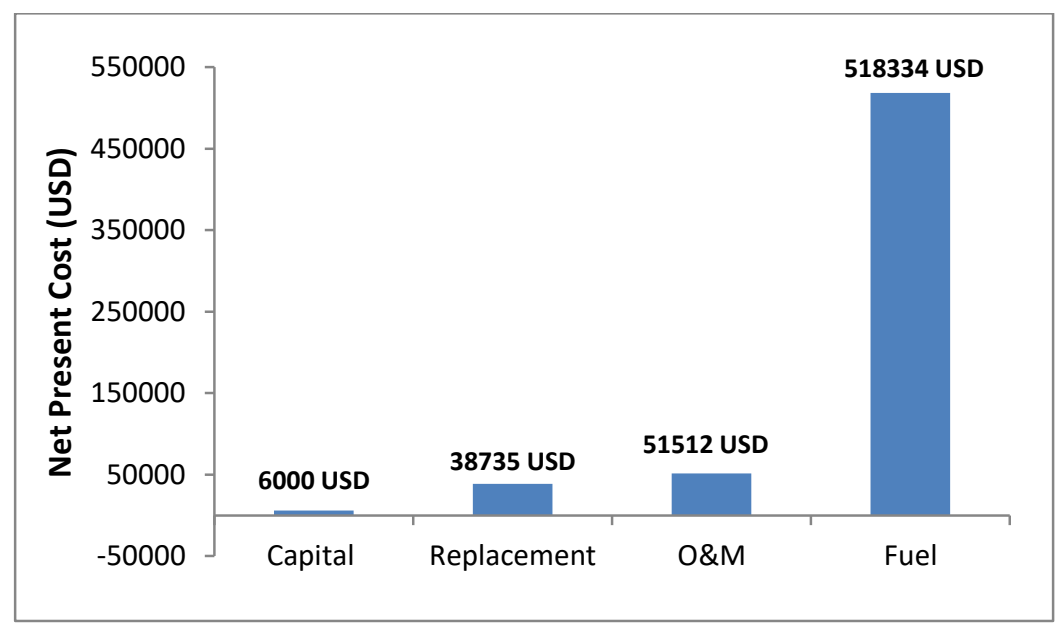

Fig. 9 Summary of cash flow (net present cost) for the stand alone diesel system

\section{B. PV/Diesel hybrid system without battery system}

The graphs for the cost of energy (COE) and the net present cost (NPC) for the PV/diesel hybrid system without battery storage are shown in Fig. 10a and 10b respectively, while the graph for excess electricity generated by the hybrid system and the level $\mathrm{CO}_{2}$ emission against three different PV rating of $10 \mathrm{~kW}, 15 \mathrm{KW}$ and $20 \mathrm{~kW}$ is depicted in Fig. 10c and Fig. 10d respectively. It can be observed that the values of the NPC and COE increase as the PV capacity is increased from $10 \mathrm{~kW}, 15 \mathrm{~kW}$ and $20 \mathrm{~kW}$. This is because the PV capacity is directly proportional to PV cost. This means that as the PV capacity is increased, the cost of PV will also increase. Also, it is a clear indication that the higher the PV capacity, the higher the excess electricity generated and the lower the level of $\mathrm{CO}_{2}$ emission. During the daytime, when the PV generates excess electricity that is greater than the load demand, the excess electricity being generated would be just a waste since there is no storage battery in this system configuration. The amount of $\mathrm{CO}_{2}$ release by the hybrid PV/diesel is about 91,990- 94832 $\mathrm{kg} / \mathrm{year}$ based on different PV ratings. Fig. 10d shows the reduction in $\mathrm{CO}_{2}$ emission against different power ratings of the PV. The amount of $\mathrm{CO}_{2}$ emission is less in this system when compared with that of the standalone diesel system. 
The electricity generated by the PV panels and level of penetration of the PV in the hybrid system is shown in Table II. The PV penetration into the system and the PV energy production of the same capacity will be similar throughout the simulation period.

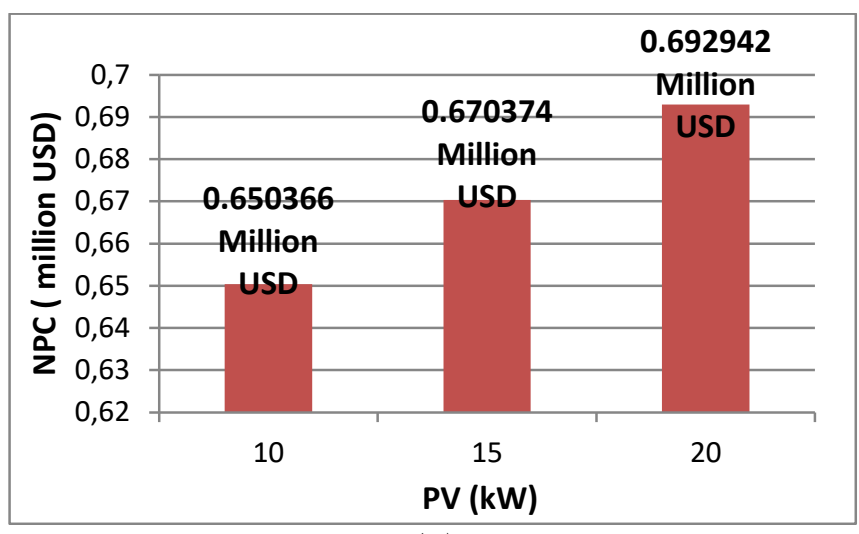

(a)

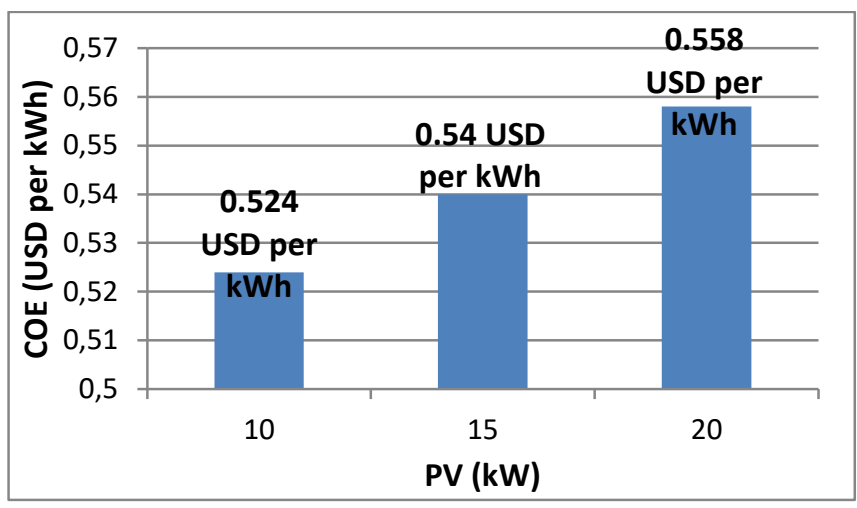

(b)

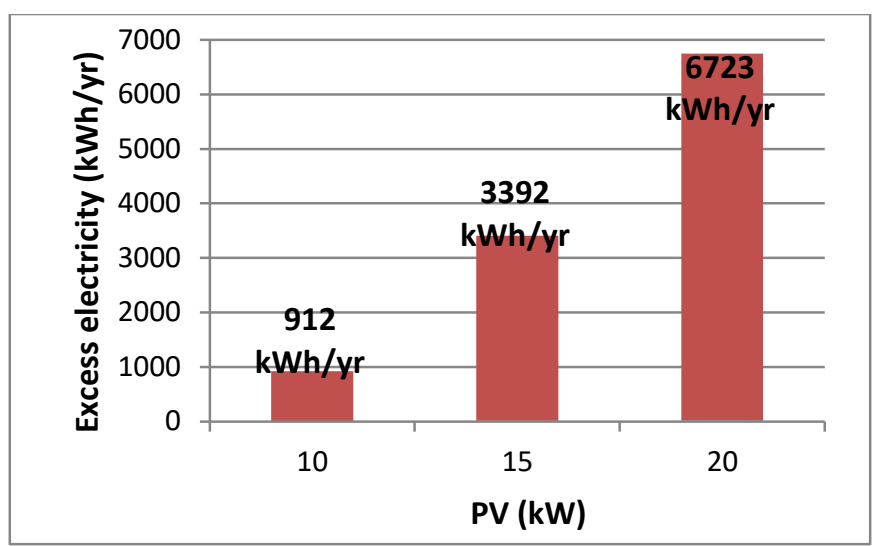

(c)

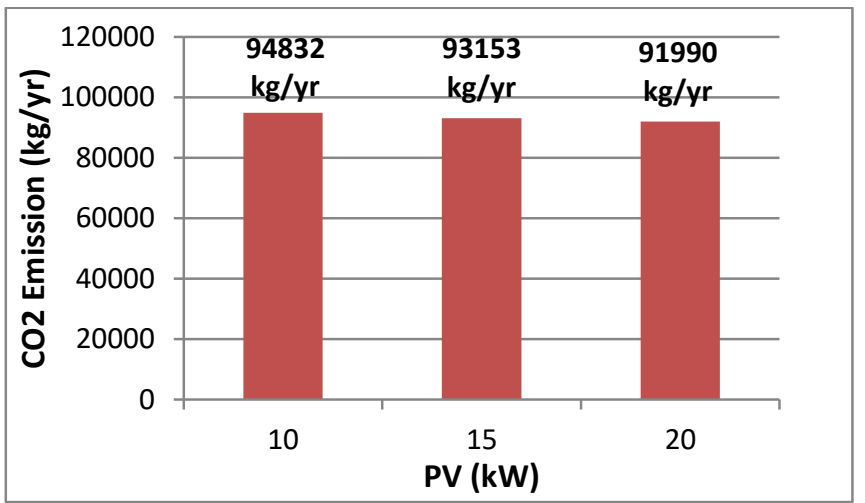

(d)

Fig. 10. The results obtained at the end of the simulation for the hybrid PV/diesel without battery: (a) the graph of Net present Cost (NPC) against different PV capacity, (b) Shows the Cost of Energy (COE) values against different PV rating (c) Shows the excess electricity produced against different $\mathrm{PV}$ rating and (d) The $\mathrm{CO} 2$ emission against different $\mathrm{PV}$ capacity.

TABLE II: HYBRID PV/DIESEL SYSTEM CONFIGURATION WITHOUT BATTERY ENERGY YIELD

\begin{tabular}{llll}
\hline \hline PV $(\mathrm{KW})$ & $(\%)$ Of PV PENETRATION & PV PRODUCTION & $\begin{array}{l}\text { TOTAL ELECTRICITY } \\
\text { PRODUCTION OF THE } \\
\text { INTO THE SYSTEM }\end{array}$ \\
SYSTEM (kWh/YEAR) & & 98,094 \\
10 & & 10,1111 & 100,600 \\
15 & 10.4 & 15,166 & 103,947 \\
\hline \hline
\end{tabular}

Fig. 11b shows the graph for the cost of energy versus

\section{PV/Diesel hybrid system with battery system}

The Net present cost (NPC) for three different PV ratings against versus number of batteries is shown in Fig.

11a. It can be noticed in the figure that for the $15 \mathrm{~kW}$ and 20 $\mathrm{kW}$ PV ratings, the values of the NPC decreases from 4 units to 8 units of battery, and then the values for their NPC start to increase from 12 units to 40 units of batteries. But for the $10 \mathrm{~kW}$ PV rating, the NPC values directly increase with the number battery. The lowest NPC value in the simulation is the system with $10 \mathrm{~kW}$ PV a rating and 4 units of battery, it has about 0.655165 million USD. Followed by the NPC for the system with $15 \mathrm{~kW}$ and a $20 \mathrm{~kW} \mathrm{PV} \mathrm{rating,}$ each with 8 units of battery are 0.667025 USD million and 0.668821 USD million respectively. different numbers of battery. The graph is quite similar in pattern to that of the (NPC) graph, because the COE values and NPC are directly related to each other. The configuration with a $15 \mathrm{~kW}$ PV rating and with 40 units of battery has the highest COE of about 0.573 USD per kWh, while the configuration with a $10 \mathrm{~kW}$ PV rating and with 4 units of battery has the lowest COE of about 0.528 USD per kWh.

Fig. 11c shows the graph for percentage of excess electricity produced by the $10 \mathrm{~kW}, 15 \mathrm{~kW}$ and $20 \mathrm{~kW} \mathrm{PV}$ capacity as a function of numbers of battery. It can be noticed from the graph that, as the number of batteries is increasing, the lesser the percentage of excess electricity produced. This is an indication that more energy can be stored for utilization for the system configuration with many battery units. 
In Fig. 11d, shows the graph of the level of $\mathrm{CO}_{2}$ emission with respect to number battery is depicted. The level of $\mathrm{CO}_{2}$ emission decreases as the PV capacity increases. It can be noticed from the graph, the level of emission for $20 \mathrm{~kW}$ PV with 40 unit battery is drastically reduced when compared with the level of emission for the system configuration with $10 \mathrm{~kW}$ capacity and 4 units of batteries.

Based on simulation result performed by HOMER for the hybrid PV/diesel system with battery, the configuration with $10 \mathrm{~kW}$ and 4 units of battery is considered as the best due it lowest COE and NPC values, which are 0.528 USD per $\mathrm{kWh}$ and 0.655166 million USD (655166 USD) respectively. These values are a little bit higher with 0.033 USD per $\mathrm{kWh}$ and 0.41089 million USD (41089 USD) when compared with the results obtained for the COE and NPC of the standalone diesel system.

Fig. 12 shows the cash flow summary for the best system configuration for the hybrid PV/diesel with $10 \mathrm{~kW}$ PV capacity and 4units of batteries. Due to the high cost of PV module, the capital cost of the system is greater than that of the standalone diesel system with about 66400 USD. Also, it can be noticed that the cost of fuel cost in running the system is considerably high. This is because the generator produced about $90 \%$ of the total electricity that is being generated. The cost of fuel in this system when compared with the standalone diesel system is less by 32269 USD.

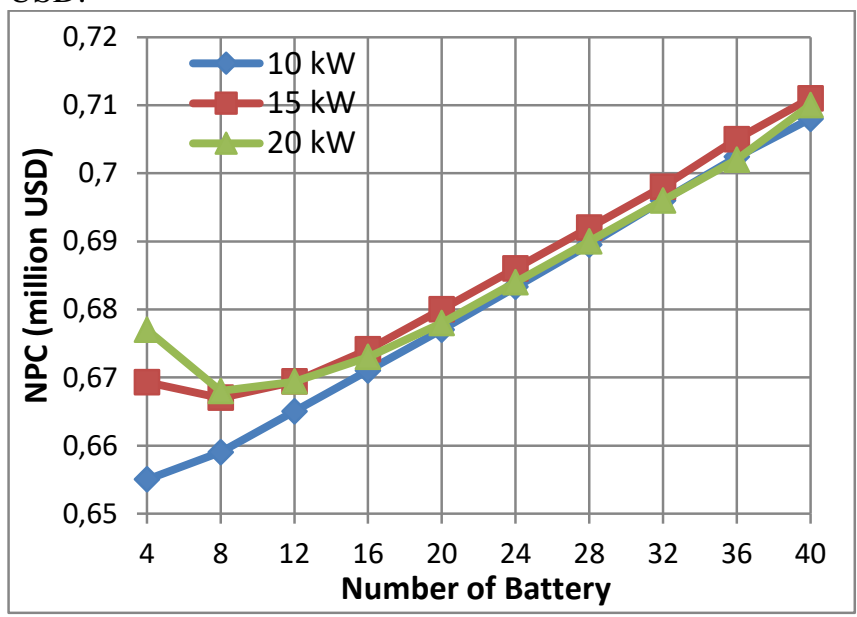

(a)

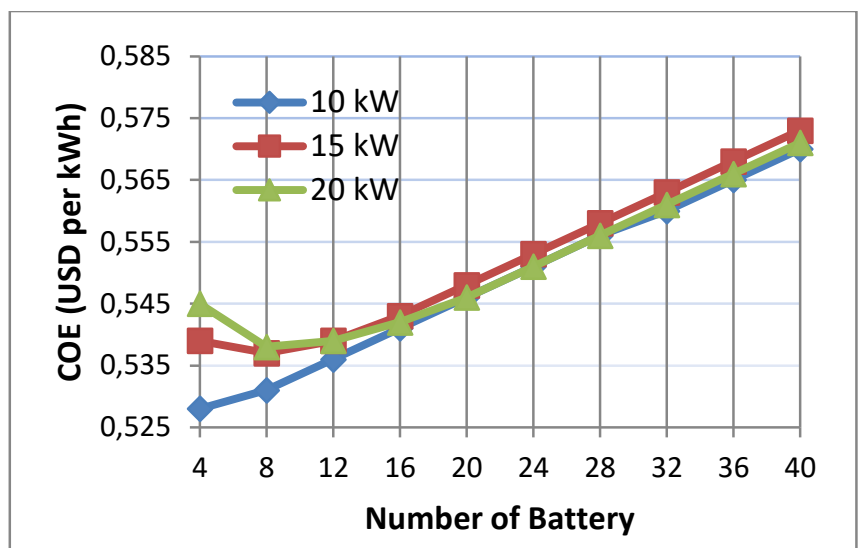

(b)

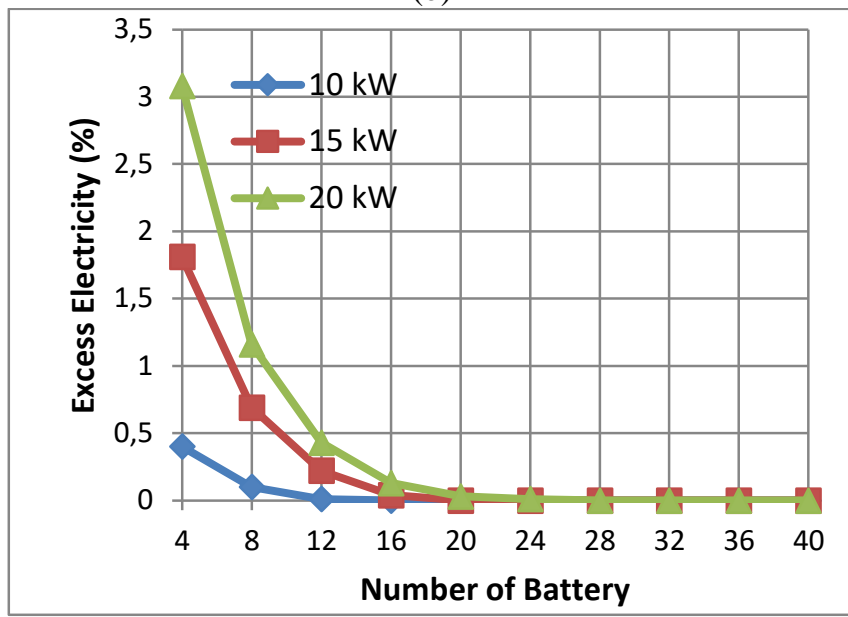

(c)

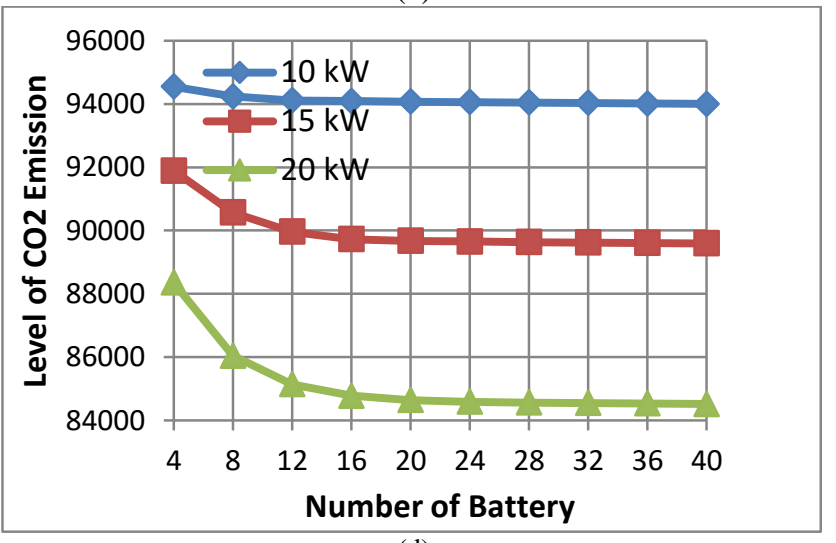

(d)

Fig. 11. The results obtained from the simulation of Hybrid PV-Diesel with battery storage (a), (b), (c ) \& (d) Shows the Net Present Cost, Cost of Energy, Excess electricity (\%) and Level of Emission against different number of battery for three of different PV ratings $(10 \mathrm{~kW}, 15 \mathrm{~kW}$ and $20 \mathrm{~kW})$ 


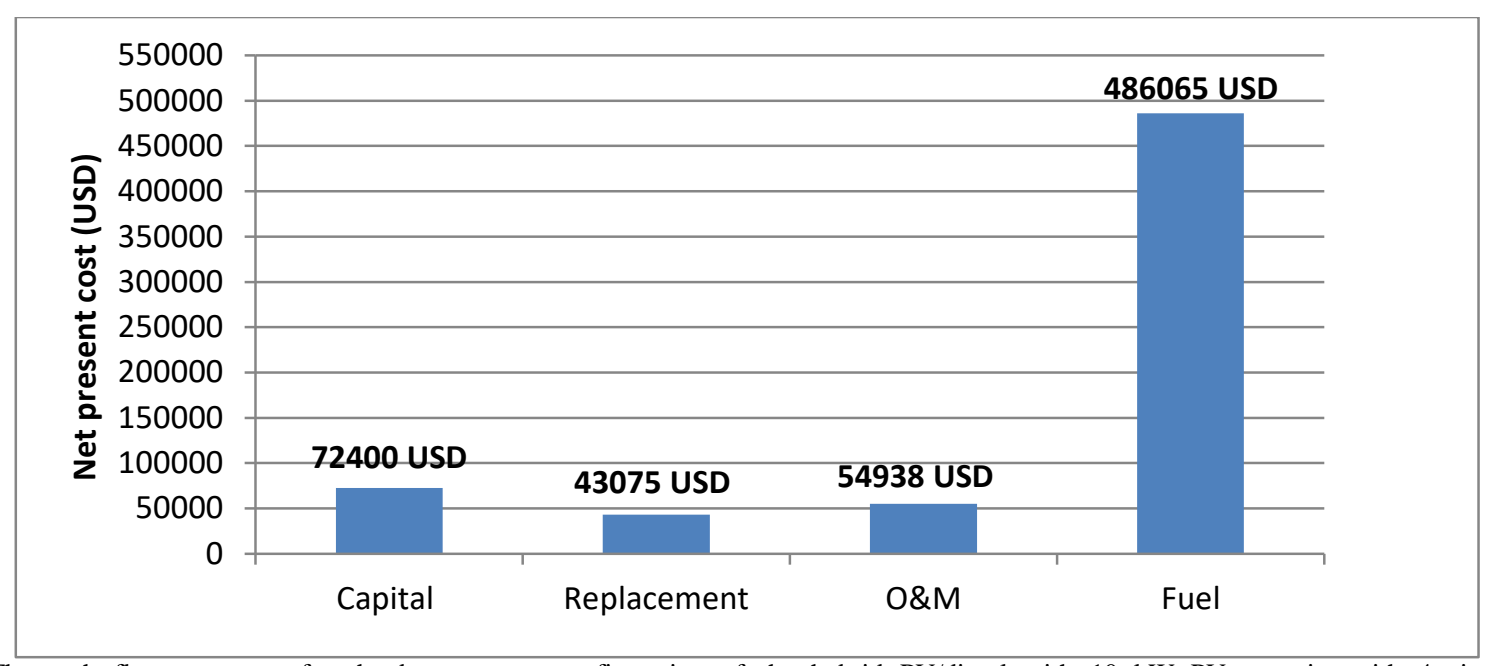

Fig. 12. The cash flow summary for the best system configuration of the hybrid PV/diesel with $10 \mathrm{~kW} \mathrm{PV} \mathrm{capacity} \mathrm{with} \mathrm{4units} \mathrm{of} \mathrm{battery}$

TABLE III: SHOWS THE OVERALL SIMULATION RESULT FOR THE INPUT DATA

\begin{tabular}{|c|c|c|c|c|c|c|c|c|c|}
\hline $\begin{array}{c}\text { PV } \\
(\mathbf{k W})\end{array}$ & $\begin{array}{c}\text { Gen } \\
(\mathbf{k W})\end{array}$ & S6CS25P & $\begin{array}{c}\text { Conv. } \\
(\mathrm{kW})\end{array}$ & $\begin{array}{c}\text { Initial } \\
\text { Cost }\end{array}$ & $\begin{array}{l}\text { Operating } \\
\text { cost }(\$ / y r)\end{array}$ & $\begin{array}{c}\text { Total } \\
\text { NPC }(\$) \\
\end{array}$ & $\begin{array}{c}\text { COE } \\
(\$ / k W h) \\
\end{array}$ & $\begin{array}{c}\text { Ren. } \\
\text { Fraction } \\
\end{array}$ & $\begin{array}{r}\begin{array}{c}\text { Diesel } \\
\text { (litres) }\end{array} \\
\end{array}$ \\
\hline- & 20 & - & 20 & 6,000 & 47,568 & 614,077 & 0.495 & 0.00 & 38,289 \\
\hline- & 20 & 4 & 20 & 16,400 & 48,009 & 630,115 & 0.508 & 0.00 & 38,285 \\
\hline- & 20 & 8 & 20 & 20,800 & 48,148 & 636,293 & 0.513 & 0.00 & 38,281 \\
\hline - & 20 & 12 & 20 & 25,200 & 48,287 & 642,471 & 0.518 & 0.00 & 38,276 \\
\hline - & 20 & 16 & 20 & 29,600 & 48,429 & 648,681 & 0.523 & 0.00 & 38,273 \\
\hline 10 & 20 & - & 20 & 68,000 & 45,557 & 650,366 & 0.524 & 0.10 & 36,012 \\
\hline- & 20 & 20 & 20 & 34,000 & 48,565 & 654,827 & 0.528 & 0.00 & 38,267 \\
\hline 10 & 20 & 4 & 20 & 72,400 & 45,588 & 655,166 & 0.528 & 0.10 & 38,905 \\
\hline 10 & 20 & 8 & 20 & 76,800 & 45,579 & 659,456 & 0.531 & 0.10 & 35,787 \\
\hline- & 20 & 24 & 20 & 38,400 & 48,704 & 661,005 & 0.533 & 0.00 & 38,262 \\
\hline 10 & 20 & 12 & 20 & 81,200 & 45,660 & 665,884 & 0.537 & 0.10 & 35,738 \\
\hline 15 & 20 & 8 & 20 & 104,800 & 43,981 & 667,025 & 0.537 & 0.15 & 34,392 \\
\hline- & 20 & 28 & 20 & 42,800 & 48,841 & 667,151 & 0.538 & 0.00 & 38,256 \\
\hline 20 & 20 & 8 & 20 & 132,800 & 41,893 & 668,339 & 0.538 & 0.20 & 32,675 \\
\hline 20 & 20 & 12 & 20 & 137,200 & 41,587 & 668,821 & 0.539 & 0.21 & 32,334 \\
\hline 20 & 20 & 16 & 20 & 141,600 & 41,549 & 672,735 & 0.542 & 0.21 & 32,196 \\
\hline- & 20 & 32 & 20 & 47,200 & 48,980 & 673,329 & 0.543 & 0.00 & 38,251 \\
\hline 20 & 20 & 20 & 20 & 146,000 & 41,622 & 678,075 & 0.546 & 0.21 & 32,143 \\
\hline 20 & 20 & 40 & 20 & 168,000 & 42,285 & 708,545 & 0.571 & 0.21 & 32,096 \\
\hline 15 & 20 & 40 & 20 & 140,000 & 44,651 & 710,784 & 0.573 & 0.16 & 34,023 \\
\hline
\end{tabular}

\section{CONCLUSION}

HOMER optimization software has simulated 45 different system configurations for the remote village of Garundole as shown in the overall simulation for the input data in table III. The system studied include hybrid PV/diesel without battery, hybrid PV/diesel with a battery and a standalone diesel system. The simulation was carried out using three different diesel prices, i.e. 1.059, 0.73 and 1.46 USD per litre. The study revealed that the standalone diesel system has the lowest cost of energy and net present cost as when compared with the hybrid PV/diesel system with battery storage this may be as a result of lack of government support in implementing renewable energy as alternative source energy in Nigeria. Although the standalone the system with the cheapest cost of energy emit high amount of $\mathrm{CO}_{2}$ every year and is ranked highest in term of emission among all the studied system configurations. The standalone diesel system is therefore not regarded as the best option in this case. The PV/diesel hybrid system without battery system is ranked as the second cheapest in term of cost of energy, although it is still not the best option, as excess electricity produced during the day time would be a waste as there is no storage element provided to accommodate the electricity produced by the PV.

In conclusion, the proposed PV/diesel hybrid system with a battery system stands out to be the best option. The system has more advantages over the two system mention earlier, especially the PV/diesel with $10 \mathrm{~kW}$ PV capacity 
with 4 units of battery which has less level of green greenhouse gasses, less cost of energy, less net present cost and the amount of excess electricity produced is quite less compare to the other studied configuration. Moreover the system capacity can be easily upgraded for future demand if the need arises.

\section{REFERENCES}

[1] Shaaban, M. and J. Petinrin, Renewable energy potentials in Nigeria: Meeting rural energy needs. Renewable and Sustainable Energy Reviews, 2014. 29: p. 72-84.

[2] Mohammed, Y., et al., Renewable energy resources for distributed power generation in Nigeria: a review of the potential. Renewable and Sustainable Energy Reviews, 2013. 22: p. 257-268.

[3] Sambo, A.S., Strategic developments in renewable energy in Nigeria. International Association for Energy Economics, 2009. 16.

[4] Dasappa, S., Potential of biomass energy for electricity generation in sub-Saharan Africa. Energy for Sustainable Development, 2011. 15(3): p. 203-213.

[5] Adaramola, M. and O. Oyewola, On wind speed pattern and energy potential in Nigeria. Energy Policy, 2011. 39(5): p. 2501-2506.

[6] Chineke, T.C. and F.M. Ezike, Political will and collaboration for electric power reform through renewable energy in Africa. Energy Policy, 2010. 38(1): p. 678-684.

[7] Shaahid S. M. and Elhadidy M. A., "Technical and economic assessment of grid-independent hybrid photovoltaic-diesel-battery power systems for commercial loads in desert environments," Renewable and Sustainable Energy Reviews, vol. 11, pp. 1794-1810, 2007.

[8] SolarGis, Maps of Global horizontal irradiation (GHI). (C) 20102015 GeoModel Solar.

[9] (US), U.S. National Renewable Energy Labouratory (NREL) http://analysis.nrel.gov/homer [accessed 09.10.10]

[10] Farret, F.A. and M.G. Simoes, Integration of alternative sources of energy. 2006: John Wiley \& Sons.

[11] Information, W.W.a.C. Average weather in Maiduguri, Nigeria http://www.weather-and-climate.com/average-monthly-RainfallTemperature-Sunshine,Maiduguri,Nigeria. [accessed 27.09.14].

[12] Limited, G.P. The Solar Electricity Handbook, Solar irradiance calculator http://www.solarelectricityhandbook.com/solarirradiance.html [accessed 23.08.14].

[13] Market, I. Diesel Price www.globalpetrolprices.com/diesel [accessed 07.08.14]

[14] $250 \mathrm{~W}$ Poly crystalline solar panel http://www.alibaba.com/productdetail/High-quality-250w-poly-pv-solar_1584698651.html [accessed 28.09.14].

[15] Cummins power silent diesel generator price generation, http://www.alibaba.com/product-detail/100kva-80kw-cumminspower-silent-diesel_514256041.html [accessed 26.09.14].

[16] JKS-Pure-Sine-Wave-Inverter http://www.alibaba.com/productdetail/JKS-Pure-Sine-Wave-Inverter-1_550235865.html [accessed 28.09.14]

[17] Surrette 6CS-21PS Solar Battery http://www.wholesalesolar.com/products.folder/batteryfolder/Surretterolls.html [accessed 28.09.14].

[18] Li, C.-H., et al., Dynamic modeling and sizing optimization of standalone photovoltaic power systems using hybrid energy storage technology. Renewable Energy, 2009. 34(3): p. 815-826.

[19] Nema, P., R. Nema, and S. Rangnekar, A current and future state of art development of hybrid energy system using wind and $P V$-solar: $A$ review. Renewable and Sustainable Energy Reviews, 2009. 13(8): p. 2096-2103.

[20] Lau, K.Y., et al., Performance analysis of hybrid photovoltaic/diesel energy system under Malaysian conditions. Energy, 2010. 35(8): p. 3245-3255.

[21] Swisher, J.N. and R.Y. Gilberto de MJ, Integrated resource planning-improving energy efficiency and protecting the environment. UNEP Collaborating Centre on Energy and Environment, Denmark, 1997.

[22] Mukhtaruddin, R. N. S. R., Rahman, H. A., \& Hassan, M. Y. (2013, June). Economic analysis of grid-connected hybrid photovoltaicwind system in Malaysia. In Clean Electrical Power (ICCEP), 2013 International Conference on (pp. 577-583). IEEE.

[23] Nigeria, Central Bank, Inflation Rates (Per cent). http://www.cenbank.org/rates/inflrates.asp [accessed 7.12.14].

[24] Bank, T.W. Real interest rate (\%).http://data.worldbank.org/indicator/FR.INR.RINR [accessed 07.12.14].
[25] Ngan, M.S. and C.W. Tan, Assessment of economic viability for PV/wind/diesel hybrid energy system in southern Peninsular Malaysia. Renewable and Sustainable Energy Reviews, 2012. 16(1): p. 634-647. 